\title{
Enzyme heterozygosity associated with anatomical character variance and growth in the herring (Clupea harengus L.)
}

\author{
D. P. F. King
}

\author{
Department of Agriculture for Northern Ireland, \\ Fisheries Research Laboratory, 38 Castleroe Road, \\ Coleraine, Co. Londonderry, BT51 3RL, United \\ Kingdom.
}

\begin{abstract}
The hypothesis that enzyme heterozygosity is positively related to phenotypic characteristics in fish was tested using five polymorphic enzyme loci and seven anatomical characteristics in samples of North Irish Sea herring, Clupea harengus. Though not unambiguous the results indicated that heterozygosity was associated with increased developmental stability. Also, multiple homozygosity was negatively correlated with growth parameter estimates. Though no single locus correlates were evident, the level of multiple heterozygosity of an individual appeared to be positively related to body length.
\end{abstract}

\section{INTRODUCTION}

Lerner (1954) reported that, in crosses between domesticated strains of plants and animals, inbreeding leads initially to a decrease in phenotypic variance but that the increased homozygosity eventually leads to an increase in morphological variability. He concluded that highly heterozygous individuals have enhanced developmental homeostasis and often exhibit positive heterosis. Much of the early work on genetic variation associated with phenotypic variability was focused on laboratory populations. Furthermore, these studies often involved substantial changes in genetic variability, such as are produced when entire chromosomes are made homozygous (Eanes, 1978).

Multiple heterozygosity has recently been related to decreased morphological variance and asymmetry in several organisms (e.g., killifish, Fundulus heteroclitus, Mitton (1978); monarch butterfly, Danus plexippus, Eanes (1978); rainbow trout, Salmo gairdneri, Leary et al. (1983); house sparrow, Passerdomesticus, Fleischer et al. (1983)). Moreover, several studies on the amount of enzyme variation in natural populations have revealed a positive correlation between average heterozygosity and growth rate, e.g., American oysters, Crassostrea virginica (Singh and Zouros, 1978); sunfish, Micropterus spp. (Wheat et al., 1974); mosquito fish, Gambusia affinis (Smith and Chesser, 1981); brown trout, Salmo trutta (Taggart, 1981).

The importance of the above studies is of interest on both theoretical and applied grounds, and so these relationships should be investigated further, especially in natural populations. Results are presented here of an examination of the relationship between heterozygosity at several enzyme loci and the variance of anatomical characters in the Atlantic herring, Clupea harengus L., the relationship between heterozygosity and length is also studied.

\section{MATERIAL AND METHODS}

Data were taken from an investigation of the genetics and morphometrics of herring stocks to the West of the British Isles (King, 1983).

A total of 20 samples were used, comprising 12 samples (1172 specimens) of North Irish Sea Mourne herring and eight samples ( 738 specimens) 
of North Irish Sea Manx herring. All specimens were mature fish collected immediately prior to spawning. The material was collected between September 1979 and October 1981 by trawl and drift nets. The fish were kept on ice for up to 24 hours before preparation of heart, liver and skeletal muscle tissue samples. These were immediately frozen and stored for up to 3 months at $-25^{\circ} \mathrm{C}$ before electrophoretic analysis. Total length, weight, age (from otoliths) and sex were recorded for each specimen. In addition, these specimens were characterised for their number of anal fin rays (AFR), pectoral fin rays (PFR), vertebral count (VS), gill rakers number (GRN), pectoral fin length (expressed as a ratio of total length, PFLLT) and otolith morphology (the length of the first hyaline winter ring, $O$, and the ratio between the postrostrum and pararostrum, PAPO). These measurements and counts were made according to criteria established by King (1983).

Tissue extracts were prepared and starch gel electrophoresis was performed following the methods of Ferguson (1980). Staining recipies for enzymes followed those of Harris and Hopkinson (1976). Although in Atlantic herring polymorphism has been detected at 14 loci encoding 11 enzymes (King, 1983), the most of the variability is distributed among 5 loci: Esterase 4 (Est-4), Lactate dehydrogenase-2 (Ldh-2), Malate dehydrogenase-4 (Mdh-4), Phosphoglucomutase-2 (Pgm-2) and Phosphoglucose isomerase (Pgi). With the exception of Pgi, which displays seven electrophoretically detectable alleles these loci each possess two variant alleles. These five loci form the basis of the present investigation. More complete explanations of laboratory procedures are given in King (1983); additional details are available on request.

\section{DATA ANALYSIS}

\section{(i) Enzyme heterozygosity and anatomical variance}

Allelic frequencies and genetic variability statistics for individual samples are presented in detail elsewhere (King, 1983). Consideration for the genotype frequencies revealed that there was a marked excess of homozygosity for the Est-4 locus in six of the 20 samples examined (King, 1983). Genotype frequencies at the other four loci did not deviate significantly from Hardy-Weinberg equilibrium in any of the samples (King, 1983).

Univariate statistics of the anatomical characteristics of these samples are presented in King
(1983). Within each sample the distributions of all seven characters were approximately normal (King, 1983). Correlation between characters was statistically non significant (King, 1983). Thus, all the examined characters are expected to be largely developmentally unrelated to one another.

Analysis of variance showed no significant $(P>0.05)$ anatomical variation between samples within locality (Mourne or Manx). Samples from within each locality (population) were, therefore, combined for the subsequent analyses. Likewise, results for males and females and for different ages were pooled within each locality since tests of both sex and sex $\times$ location interaction effects, and age and age $\times$ location interaction effects for each anatomical character were non-significant $(P>0.05)$. Significant heterogeneity $(P<0.05)$ among means, due to locality differences, were detected for all characters (King, 1983). Therefore, the two localities were analysed separately. For each locus the data was divided into two groups, those individuals heterozygous for that locus and those homozygous. The relationship between phenotypic variation and enzyme heterozygosity was analysed by comparing the character variances of homozygotes and heterozygotes at each locus by a twotailed $F$ test $\left(H_{0}: \sigma^{2}\right.$ homozygotes $=\sigma^{2}$ heterozygotes).

The relationship between anatomical character variation and the number of heterozygous loci per individual (multi-locus heterozygosity) was examined using the procedure adopted by McAndrew et al. (1982). Each fish was assigned a heterozygous score ranging from 0 (homozygous at all loci) to 5 (heterozygous at all loci). The variance for each anatomical character for each of the genotypic classes was then calculated and weighted regressions of variance on heterozygosity computed. A progressive decrease in variance as multi-locus heterozygosity increases would support the hypothesis that increased heterozygosity is associated with reduced phenotypic variability (McAndrew et al., 1982).

\section{(ii) Genetic variation associated with growth}

The samples used in this analysis consisted only of herring collected on the Mourne spawning grounds. From this data set, four samples were excluded because they had insufficient age classes for inclusion in the adopted test procedure.

As in the previous analysis, in the absence of a significant difference in enzyme variability or in growth between the two sexes those data were combined for subsequent analysis. 
Within each sample measurements of length at age were separated into those measurements for individuals heterozygous for any of the test loci and those from individuals homozygous at all loci. For each sample, the von Bertalanffy growth equation, $L=L_{\infty}\left[1-\exp \left(-K t+K t_{0}\right)\right]$, was fitted to these data and estimates of asymptotic length $\left(L_{\infty}\right)$, the coefficient of growth $(K)$, time at which length is zero $\left(t_{0}\right)$, and their variance-covariance matrices computed. The data were initially subjected to univariate statistical analysis using the $t$-test. Multivariate statistical analysis testing all differences in parameters simultaneously was accomplished using the Mahalanobis $D^{2}$ statistic. The calculated $D^{2}$ statistic was used to test the hypothesis $H_{0}: d=0$. The significance of which is tested by comparison with a critical $D_{0}^{2}$ derived as outlined by Marriott (1974).

\section{RESULTS \\ (i) Enzyme heterozygosity and anatomical variance}

A total of 70 tests ( 7 anatomical characters $\times 5$ genetic loci $\times 2$ spawning localities) were carried out and the results presented in Table 1.

Table 1 Variance ratio test for differences in the variance of anatomical characters between fish homozygous (Hom) or heterozygous (Het) at each of 5 enzyme loci

\begin{tabular}{|c|c|c|c|c|c|c|c|}
\hline \multirow[b]{2}{*}{$\S$ Locus } & \multirow[b]{2}{*}{${ }^{\$}$ Character } & \multicolumn{3}{|c|}{ Mourne } & \multicolumn{3}{|c|}{$\operatorname{Man} x$} \\
\hline & & $\operatorname{Hom}(n)$ & Het $(n)$ & $F$ & $\operatorname{Hom}(n)$ & Het $(n)$ & $F$ \\
\hline \multirow[t]{7}{*}{ Est -4} & AFR & $0.606(548)$ & $0.637(210)$ & 0.95 & $0.994(352)$ & $0.976(94)$ & $1 \cdot 01$ \\
\hline & PFR & $0.610(549)$ & $0.530(218)$ & $1 \cdot 15$ & $0.567(289)$ & $0.520(96)$ & 1.09 \\
\hline & GRN & $1.480(530)$ & $1 \cdot 540(215)$ & 0.96 & $1 \cdot 273(346)$ & $1.419(92)$ & 0.90 \\
\hline & VS & $0.453(556)$ & $0.410(216)$ & $1 \cdot 10$ & $0.485(352)$ & $0.464(92)$ & 1.05 \\
\hline & PFLLT & $50 \cdot 300(557)$ & $46 \cdot 500(219)$ & $1 \cdot 08$ & $42 \cdot 090(357)$ & $34 \cdot 290(95)$ & $1 \cdot 23$ \\
\hline & PAPO & $4 \cdot 123(564)$ & $2 \cdot 703(217)$ & $1 \cdot 53 \$$ & $2 \cdot 653(355)$ & $3 \cdot 220(93)$ & 0.89 \\
\hline & $\mathrm{O}_{1}$ & $11 \cdot 800(549)$ & $10 \cdot 350(215)$ & $1 \cdot 14$ & $10.990(340)$ & $9 \cdot 950(92)$ & $1 \cdot 10$ \\
\hline \multirow[t]{7}{*}{$L d h-2$} & AFR & $0.603(557)$ & $0.432(55)$ & $1 \cdot 40^{*}$ & $0.787(382)$ & $0.716(29)$ & $1 \cdot 09$ \\
\hline & PFR & $0.800(596)$ & $0.580(57)$ & $1 \cdot 38^{*}$ & $0.557(390)$ & $0.453(29)$ & $1 \cdot 23$ \\
\hline & GRN & $1.470(589)$ & $1.410(58)$ & $1 \cdot 04$ & $1.442(376)$ & $1 \cdot 242(28)$ & $1 \cdot 16$ \\
\hline & VS & $0.589(606)$ & $0.433(60)$ & $1 \cdot 36^{*}$ & $0.489(368)$ & $0.432(25)$ & $1 \cdot 13$ \\
\hline & PFLLT & $97 \cdot 800(602)$ & $96 \cdot 100(61)$ & 1.02 & $41 \cdot 150(387)$ & $37 \cdot 350(28)$ & $1 \cdot 10$ \\
\hline & PAPO & $3.896(610)$ & $2 \cdot 812(59)$ & $1 \cdot 39^{*}$ & $3 \cdot 792(383)$ & $3 \cdot 451(29)$ & $1 \cdot 09$ \\
\hline & $O_{1}$ & $11 \cdot 800(597)$ & $10 \cdot 510(58)$ & $1 \cdot 12$ & $12 \cdot 690(369)$ & $11 \cdot 420(29)$ & $1 \cdot 11$ \\
\hline \multirow[t]{7}{*}{$M d h-4$} & AFR & $0.606(392)$ & $0.575(385)$ & 1.05 & $0.391(218)$ & $0 \cdot 378(252)$ & $1 \cdot 03$ \\
\hline & PFR & $0.642(395)$ & $0.501(372)$ & $1 \cdot 22 *$ & $0.568(223)$ & $0.531(257)$ & $1 \cdot 07$ \\
\hline & GRN & $1 \cdot 500(400)$ & $1 \cdot 520(378)$ & 0.99 & $1 \cdot 090(211)$ & $1 \cdot 160(248)$ & 0.94 \\
\hline & VS & $0.485(390)$ & $0.405(380)$ & $1 \cdot 20^{*}$ & $0.489(245)$ & $0 \cdot 387(202)$ & $1 \cdot 26^{*}$ \\
\hline & PFLLT & $56 \cdot 500(413)$ & $43 \cdot 800(381)$ & $1 \cdot 29^{*}$ & $38 \cdot 030(222)$ & $40 \cdot 500(254)$ & 0.94 \\
\hline & PAPO & $3 \cdot 740(407)$ & $3 \cdot 220(392)$ & $1 \cdot 16$ & $2 \cdot 611(200)$ & $2 \cdot 954(263)$ & 0.88 \\
\hline & $\mathrm{O}_{1}$ & $11 \cdot 180(405)$ & $11 \cdot 380(377)$ & 0.98 & $12 \cdot 973(208)$ & $11 \cdot 053(249)$ & $1 \cdot 17$ \\
\hline \multirow[t]{7}{*}{$P g i$} & AFR & $0.574(399)$ & $0.633(376)$ & 0.91 & $1.459(224)$ & $1 \cdot 278(246)$ & $1 \cdot 14$ \\
\hline & PFR & $0.580(396)$ & $0.640(360)$ & 0.91 & $0.559(230)$ & $0.538(250)$ & $1 \cdot 04$ \\
\hline & GRN & $1 \cdot 052(437)$ & $1 \cdot 260(427)$ & $0.83^{*}$ & $1 \cdot 195(222)$ & $1 \cdot 062(237)$ & $1 \cdot 13$ \\
\hline & VS & $0.481(385)$ & $0.422(372)$ & $1 \cdot 14$ & $0.540(229)$ & $0.403(248)$ & $1 \cdot 34^{*}$ \\
\hline & PFLLT & $55 \cdot 300(402)$ & $41 \cdot 600(378)$ & $1 \cdot 33 \dagger$ & $39 \cdot 760(227)$ & $38 \cdot 900(249)$ & $1 \cdot 02$ \\
\hline & PAPO & $3.093(402)$ & $3 \cdot 221(383)$ & 0.96 & $2 \cdot 536(228)$ & $2 \cdot 855(235)$ & 0.89 \\
\hline & $\mathrm{O}_{1}$ & $12 \cdot 180(397)$ & $10 \cdot 670(371)$ & $1 \cdot 14$ & $12 \cdot 806(221)$ & $11 \cdot 104(236)$ & $1 \cdot 15$ \\
\hline \multirow[t]{7}{*}{ Pgm-1 } & AFR & $0.611(634)$ & $0.775(49)$ & 0.79 & $0.879(343)$ & $0 \cdot 889(48)$ & 0.99 \\
\hline & PFR & $0.580(526)$ & $0.730(47)$ & 0.79 & $0.537(361)$ & $0.637(49)$ & 0.84 \\
\hline & GRN & $1 \cdot 530(586)$ & $1.460(43)$ & $1 \cdot 05$ & $1.420(108)$ & $1 \cdot 071(286)$ & $1 \cdot 33^{*}$ \\
\hline & VS & $0.486(468)$ & $0.317(49)$ & $1.53 \dagger$ & $0.477(358)$ & $0.427(49)$ & $1 \cdot 12$ \\
\hline & PFLLT & $47 \cdot 900(653)$ & $56 \cdot 600(51)$ & 0.85 & $41 \cdot 080(359)$ & $36 \cdot 690(49)$ & $1 \cdot 12$ \\
\hline & PAPO & $2 \cdot 223(659)$ & $3.420(51)$ & $0.65^{*}$ & $2 \cdot 742(357)$ & $2.492(39)$ & $1 \cdot 10$ \\
\hline & $\mathrm{O}_{1}$ & $11 \cdot 910(644)$ & $10 \cdot 560(51)$ & $1 \cdot 12$ & $11 \cdot 321(369)$ & $11 \cdot 862(29)$ & 0.95 \\
\hline
\end{tabular}

\footnotetext{
Enzyme abbreviations as in text.

${ }^{\$}$ Anatomical character symbols as in text.

") $P<0.05=* ; P<0.01=\dagger ; P<0.001=\ddagger$.
} 
Because of the variability in heterozygosity levels among loci there is a considerable range of statistical power for different loci. The analysis is most powerful when the genotype classes are of approximately equal size. Positive $F$-values indicate that homozygotes are morphologically more variablie than heterozygotes. Forty-nine of the 70 comparisons show homozygotes with larger variances and 13 of these tests are statistically significant $(P<0 \cdot 05)$. With the large number of tests carried out it would be expected that three to four significant comparisons might be due to chance alone.

It is clear, however, that several of the characters showed more variance for the homozygous class as $49 / 70$ results were in the same direction $\left(\chi_{1}^{2}=11 \cdot 2 ; P<0 \cdot 001\right)$. The most significant results $(P<0.001)$ is at Est-4 for the measurement of otolith shape, PAPO in the Mourne group. It should be noted that this is the same locus for which there is an observed heterozygote deficiency (see section 3 ). Twenty-one comparisons show heterozygotes with larger variances but in only two of these tests were heterozygotes significantly more variable than homozygotes (table 1). The results are the most consistent for $L d h-2$. For this enzyme locus all comparisons showed homozygotes with larger variances and four tests were statistically significant at the 0.05 level (table 1 ). For vertebral count (VS) heterozygotes at $M d h-4$ have a significant lower $(P<0 \cdot 05)$ variance than homozygotes in both groups of herring, but no other character was statistically significant for the same locus in both herring groups.

The results from the investigation of multilocus heterozygosity and anatomical variation are given in fig. 1. An inspection of fig. 1 shows that there are no consistent trends in the relationships between the anatomical character variances examined and multi-locus heterozygosity. The calculated weighted regressions showed five positive and nine negative slopes. The only significant case was a positive regression for PAPO in the Manx data. However, three characters, vertebral count (VS), anal fin rays (AFR) and gill raker number (GRN) showed a small but progressive decrease in variance as multi-locus heterozygosity increased for both groups of herring. In all cases, the relationship was stronger for Manx fish.

\section{(ii) Genetic variation associated with growth}

Student's $t$-test comparisons of the growth parameters (considered separately) revealed no significant $(P<0.05)$ results (table 2$)$. However, asymptotic length was larger for heterozygotes $(t=$ 1.97; $P<0.10$ ) which also tend to obtain their asymptotic length at a younger age.

The multivariate analysis was carried out on the same data. An examination of the parameter estimates presented in table 3 show that the two genotypic classes of herring grew differently. The calculated $D^{2}(5 \cdot 70)$ is higher than the critical value $(5.68, P<0.05)$. Because $L_{\infty}$, was the only parameter to approach significance in the univariate analysis it is reasonable to assume that $L_{\infty}$ was the most influential in the multivariate test.

The possible correlation between growth and genetic variability was further examined by considering mean length for all ages combined and computing Student's $t$-test comparisons of mean lengths at each genotypic class at a particular locus. All five loci were thus examined. No significant differences $(P<0 \cdot 05)$ in mean length among homozygous and heterozygous classes at a single locus were found (largest $t=2 \cdot 56 ; P<0 \cdot 12$ ).

Considering the entire Mourne data as a single sample, the average length (combined across all age groups) of herring that were heterozygous at $0,1,2,3$, or $4+$ loci were determined and a weighted regression of length on multi-locus heterozygous computed (fig. 2). The results indicate a significant $(P<0.05)$ trend for increasing length with increased heterozygosity with an possible decrease at the highest levels of heterozygosity. It should be noted, however, that the length range over which the increase in size was detected is small.

\section{DISCUSSION}

The results presented here indicated that there are differences in anatomical variances between homozygous and heterozygous classes of herring. Within the limits of the accuracy of the experimental procedure employed it is suggested that these findings are congruent with the hypothesis that enzyme heterozygosity leads to reduced morphological variance. These results, therefore, agree with those of Mitton (1978) for the killifish Fundulus heteroclitus and Leary et al. (1983) for the rainbow trout Salmo gairdneri but contrast with the results of McAndrew et al. (1982) for the plaice Pleuronectes platessa. McAndrew et al. (loc. cit.), suggested that the lack of relationship between morphological variance and enzyme heterozygosity in $P$. platessa could indicate that such an association although observed by several investigators may not be a general one. 

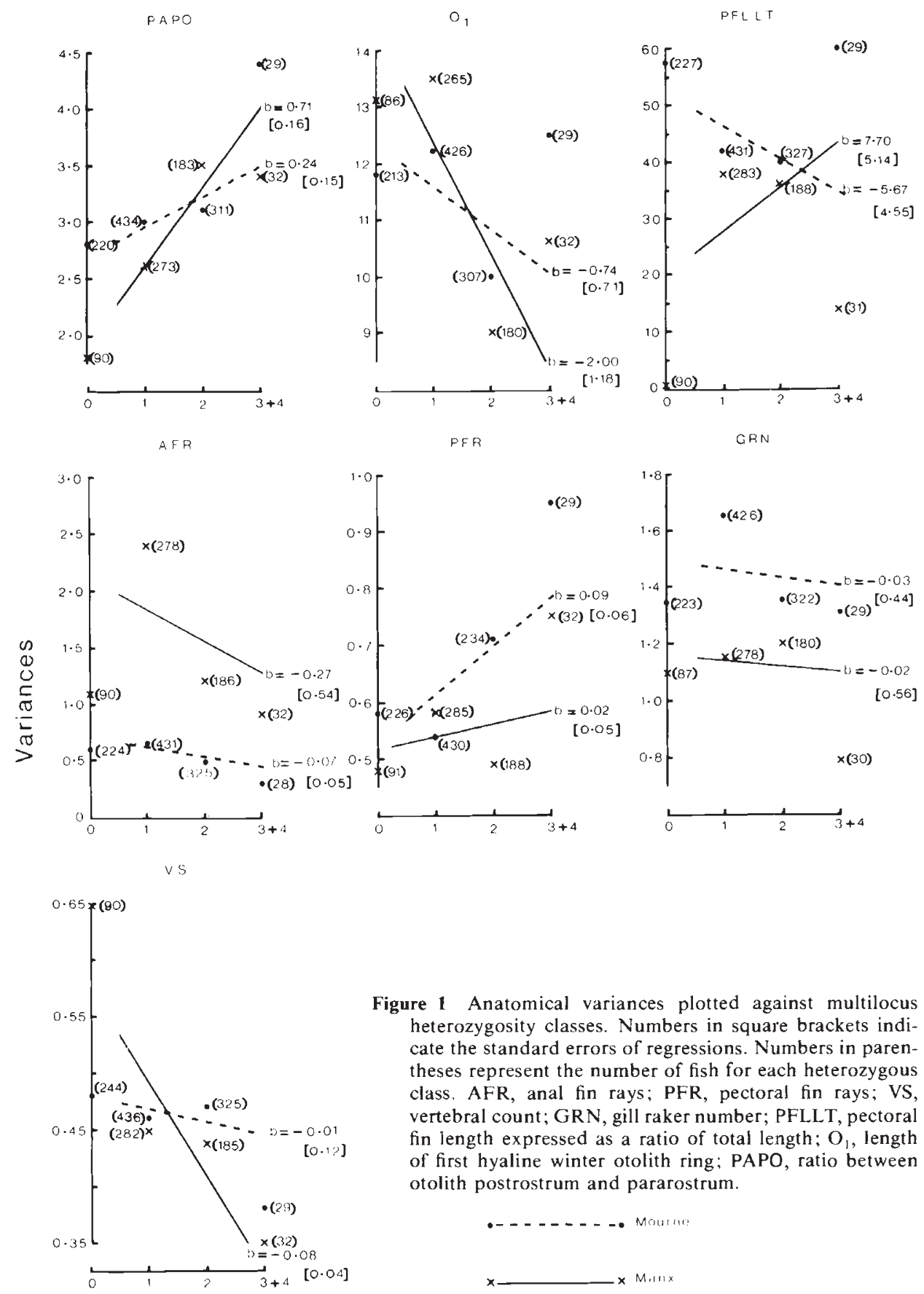

Figure 1 Anatomical variances plotted against multilocus heterozygosity classes. Numbers in square brackets indicate the standard errors of regressions. Numbers in parentheses represent the number of fish for each heterozygous class. AFR, anal fin rays; PFR, pectoral fin rays; VS, vertebral count; GRN, gill raker number; PFLLT, pectoral fin length expressed as a ratio of total length; $\mathrm{O}_{1}$, length of first hyaline winter otolith ring; PAPO, ratio between otolith postrostrum and pararostrum.

The homeostatic properties of heterozygotes, relative to homozygotes have been the subject of much discussion and theorizing in population genetics. The general conclusion is, that developmental buffering is enhanced by increased heterozygosity which reduces the environmental impact on phenotypic variance so that heterozygous individuals are closer to the centre (mean) of anatomical character distributions (Eanes, 1978; Mitton, 1978; Beardmore and Shami, 1979). While this is a possible explanation for the homeostatic properties of heterozygotes it does not 
Table 2 Parameter estimates from fitting the von Bertalanffy growth equation to mean length at age data for homozygous (Hom) and heterozygous (Het) Mourne herring

\begin{tabular}{|c|c|c|c|c|c|c|c|c|}
\hline \multirow[t]{2}{*}{ Sample number } & \multicolumn{2}{|c|}{$L_{\infty}(\mathrm{mm})$} & \multicolumn{2}{|c|}{$K$} & \multicolumn{2}{|c|}{$t_{0}$} & \multicolumn{2}{|c|}{$r$} \\
\hline & Hom & Het & Hom & Het & Hom & Het & Hom & Het \\
\hline 1 & $307 \cdot 2$ & $300 \cdot 0$ & 0.873 & 1.448 & -0.461 & $-1 \cdot 239$ & 0.418 & 0.234 \\
\hline 2 & 313.6 & $343 \cdot 8$ & $0 \cdot 343$ & 0.232 & $-2 \cdot 916$ & $-3 \cdot 920$ & 0.709 & 0.793 \\
\hline 3 & $304 \cdot 7$ & $324 \cdot 0$ & $0 \cdot 410$ & $0 \cdot 266$ & $-2 \cdot 180$ & $-3 \cdot 782$ & 0.664 & 0.767 \\
\hline 4 & $295 \cdot 4$ & $329 \cdot 4$ & 0.559 & $0 \cdot 253$ & -1.959 & $-4 \cdot 135$ & 0.572 & 0.777 \\
\hline 5 & $317 \cdot 1$ & $357 \cdot 0$ & $0 \cdot 282$ & 0.172 & $-3 \cdot 864$ & -5.694 & 0.755 & $0 \cdot 842$ \\
\hline 6 & $326 \cdot 8$ & 323.8 & $0 \cdot 200$ & 0.251 & $-5 \cdot 594$ & $-4 \cdot 260$ & 0.818 & 0.778 \\
\hline 7 & $292 \cdot 0$ & $272 \cdot 8$ & 0.382 & 0.869 & $-2 \cdot 799$ & -0.973 & 0.683 & 0.516 \\
\hline 8 & $310 \cdot 8$ & $340 \cdot 3$ & 0.661 & 0.322 & -2.770 & $-2 \cdot 770$ & 0.419 & 0.725 \\
\hline
\end{tabular}

Table 3 Results of the multivariate test between growth of homozygous and heterozygous Mourne herring. Entries include parameter estimates, pooled estimated variancecovariance matrix $(S)$, the calculated $D^{2}$ statistic and the critical $D_{0}^{2}$

homozygotes $\left\{\begin{array}{l}L_{\infty}=308.5 \mathrm{~mm} \\ K=0.464 \\ t_{0}=7.527\end{array} \quad\right.$ heterozygotes $\left\{\begin{array}{l}L_{\infty}=323.9 \mathrm{~mm} \\ K=0.477 \\ t_{0}=-6.923\end{array}\right.$
$S\left\{\begin{array}{cc}244.696 \\ -3.297, & 0.059 \\ -16.959, & 0.235, \quad 1.300 \\ D^{2}=5.70^{*}, & D_{0}^{2} 0.05 ; 3,5=5.68\end{array}\right.$

account for the deficit of numbers of heterozygotes at the Est-4 locus observed in several of the Mourne herring samples (King, 1983). This is the locus for which the most positive case in support of the hypothesis was observed. It is difficult to identify the source of this observed heterozygote deficiency. Many factors (e.g., assortative mating, population mixing, differential selection) could have been responsible for the heterozygote deficiency of Est-4 in Mourne herring. However, an adequate explanation is not yet possible.

As in previous studies (Mitton, 1978; Eanes, 1978) it is perhaps surprising to detect such an association given that only a very small part of the total genome has been investigated and that anatomical variability (as measured by seven characters) is taken as a measure of developmental homeostasis. On the other hand there is evidence from several studies that individual loci can have a strong influence on the determination of fitness in species. For instance, Mitton (1978) reported that lactate dehydrogenase (LDH) had a significant impact on fitness. It might be speculated that the present findings for LDH support this hypothesis because at this locus homozygotes gen- erally had larger variances for the anatomical characters examined compared to the heterozygotes at the same locus. However, as Mitton (1978) pointed out, it is not possible to detect whether the single locus being analysed is responsible for the observed differences, or whether it is the interaction of several loci linked to that locus on a chromosome segment. In the rainbow trout, Idh3, 4 and $P g m-1$ were two loci reported by Leary et al. (1983) to show significant single locus effects. These loci produce liver enzymes that are involved in glycolysis and the citric acid cycle, the major biochemical pathways producing the energy for metabolism during development (Leary et al., 1983). Meristic characters in fish are fixed at an early stage of embryonic development and during this period the liver is responsible for the release of stored energy. Therefore, Leary et al (1983) postulated that heterozygosity at these loci may result in a more constant and efficient flux through glycolysis and the citric acid cycle, that would result in enhanced developmental homeostasis. Accordingly, this is a possible specific mechanism to explain single locus effects on developmental stability.

Of more applied interest perhaps is the observed positive correlation between heterozygosity and growth rate. This was concluded from both the univariate and multivariate test procedures. It was further observed that this phenomenon appeared correlated with the degree of heterozygosity, that is, there was an initial increase in size with increased multilocus heterozygosity with an apparent decrease in size at higher levels of genetic variability.

In addition to herring, positive correlations between heterozygosity and growth have been observed in several other organisms. Singh and Zouros (1978) and Zouros et al. (1980) in their studies of the American oyster, Crassostrea virginica demonstrated that individual heterozygosity 


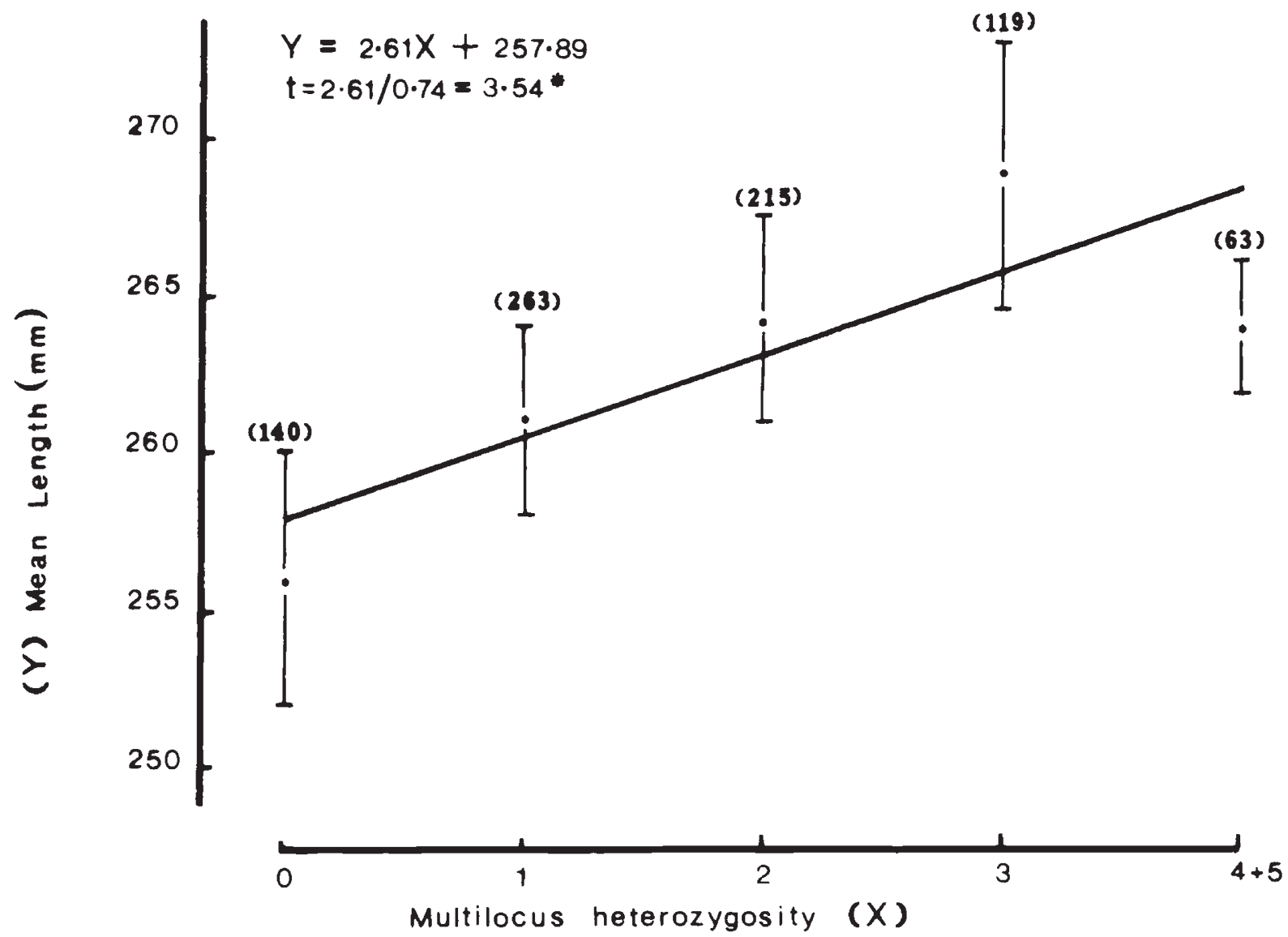

Figure 2 Mean length of Irish Sea Mourne herring plotted against multilocus heterozygosity classes. Vertical bars represent 95 per cent confidence intervals. Numbers in parentheses represent the number of fish for each heterozygous class. ${ }^{*} P<0.05$.

was positively correlated with body weight. It was further observed that the variance in weight was lower among individuals of a high degree of heterozygosity. Koehn and Shumway (1982), presented a genetic-physiological explanation for the observed differential growth rate among individuals of this species. These authors demonstrated that the more heterozygous individuals of the American oyster exhibit low oxygen consumption rates $\left(\mathrm{VO}_{2}\right)$ and suggested that when considered within the balanced energy equation (Wingerg, 1956), this genetic difference in $\mathrm{VO}_{2}$ provides an energetic explanation for the higher growth rates of the more heterozygous individuals.

In fish species, Wheat et al. (1974) in an analysis of the progeny of backcrosses involving hybrid sunfish, Micropterus spp. described a positive correlation between heterozygosity and weight involving an initial increase in weight with multi-locus heterozygosity but increasing at higher levels of variability. A similar relation with an almost iden- tical trend was described by Smith and Chesser (1981) for the adult mosquito fish, Gambusia affinis. Another similar study is that of Taggart (1981) working on a hatchery population of the Irish Brown trout $S$. trutta. He similarly reported, that up to a certain level, the overall heterozygosity of an individual appeared positively related to its size, both length and weight. Thus, although the correlation between size and the different genotypic classes of herring was not as strong as those reported above, particularly that reported for the mosquito fish, Gambusia affinis (Smith and Chesser, 1981), the general trend observed here was in close agreement with the previous observations.

Growth in fish has been found to have a considerable environmental component (Barlow, 1961). However, given that the estimates of $L_{\infty}, K$ and $t_{0}$ and their variance-covariance matrix were drawn from samples caught in the same year, it is unlikely that the ambient environment would effect 
the genotypic classes within the same year-class differentially. Furthermore, the strikingly similar results among studies would seem to suggest that this correlation between growth and heterozygosity is a real one and is not simply reflecting environmental effects or indeed random statistical error.

In this study, as in the previous ones, it is not possible to discern the causes for the observed phenomenon. Koehn and Shumway (1982), postulated that since the biochemical properties of heterozygotes are approximately intermediate between the corresponding properties of the two homozygotes, the heterotic effect on growth rate in organisms is perhaps related to the overall biochemical intermediacy of growth related metabolic reactions. Their hypothesis probably stems, in part, from the observations that in multimeric enzymes, the heteromultimers often differ from homomultimers in several aspects, sometimes restoring enzymatic activity when both homozygotes for the same enzyme lacked such activity (Zouros, 1976; and references therein). Sved et al. (1967) have proposed a hypothesis according to which the levelling off of the heterozygote advantage is explained by the existence of a threshold level of heterozygosity, above which no further advantage is obtained, only these individuals which fall below this threshold level being exposed to selection. Alternatively, conflicting overdominance effects could explain these results.

It might be stated, in conclusion, that this study provides further, evidence that morphological variability and genetic heterozygosity are related in natural populations. It was further observed that heterozygous individuals had a faster growth rate than homozygous individuals and that the degree of individual heterozygosity was positively correlated with body length. However, it is not clear what the underlying causes for these observations are, or indeed what part the enzyme polymorphisms examined here had in these associations. Whatever the actual biochemical mechanisms that affects the apparent heterozygote advantage, the theoretical and applied considerations of these findings are of obvious importance.

Acknowledgment I acknowledge gratefully Dr W. Crozier for critically reading the manuscript and for suggesting improvements. Drs A. Ferguson and J. B. Taggart made constructive comments on an early draft of this paper.

\section{REFERENCES}

BARL.OW, G. W. 1961. Causes and significance of morphological variation in fishes. Syst. Znol., 10, 105-117.

BEARIDMORE, J. A. AND SHAMI. S. A. 1979. Heterozygosity and the optimum phenotype under stabilising selection. Aquilo Ser. Zonl., 20, 100-110.

EANRS, W. F. 1978. Morphological variance and enzyme heterozygosity in the monarch butterfly. Nature, 276, 263264.

FER(BUSON, A. 1980. Biochemical Systematics and Evolution. Blackie, Glasgow.

FLEISCHER, R. ( ., JOHNST()N, R. J. AND KLITZ, W. J. 1983. Alozymic heterozygosity and morphological variation in house sparrows. Nature 304, 628-629.

HARRIS, II. ANI) HOPKINSON, D. A. 1976. Handbook of Enzyme Electrophoresis in Human Genetics. North-Holland, Amsterdam.

KING, D. P. F. 1983. Genetic and Morphometric Analyses of Atlantic Herring (Clupea harengus L.) Stocks of the West of the British Isles with Particular Reference to the North Irish Sea. Ph.D. Thesis, Queen's University, Belfast.

KOHHN, R. K. AND SHUMWAY, S. E. 1982. A Genetic/Physiological explanation for differential growth rate among individuals of the American oyster, Crassostrea virginica (Gmelin). Marine Biolngy Letiers, 3, 35-42.

LEARY, R. I., AI.I.ENDORF, F. W. AND KNUDSEN, K. L. 1983. Developmental stability and enzyme heterozygosity in rainbow trout. Nature, 301, 71-72.

Lerner, I. M. 1954. Genetic: Homeostasis. Oliver \& Boyd, Edinburgh.

MARRIOTT, F. H.C. 1974. The Interpretation of Multiple Observations. Academic Press.

MITTON, J. B. 1978. Relationship between heterozygosity for enzyme loci and variation of morphological characters in natural populations. Nature, 73, 661-662.

M( ANDREW, B. J., WARD, R. D. ANI) BEARI)MORE, J. A. 1982. Lack of relationship between morphological variance and enzyme heterozygosity in the plaice, (Pleurnnectes platessa). Heredity, 48, 117-125.

SINGH, S. M. AND ZOUROS, 1: 1978. Genetic variation associated with growth rate in the American oyster (Crassostrea virginica). Evolution, 32, 34-353.

SMITH, M. H. AND CHESSER, R. K. 1981. Rationale for conserving genetic variation of fish gene pools. Ecol. Bull, 34, $13-20$.

SVED, J. A., REEI, 'T. E. AND BODMFR. W. F. 1967. The number of balanced polymorphisms that can be maintained in a natural population. Genetics, 55, 469-481.

TAgGiart, J. B. 1981. An Electrophoretic Study of Genetic Variation in Irish Brown Trout (Salmo Trutta L.). Ph.D. Thesis, Queen's University, Belfast.

WHEAT, T. L., (IIIDERS. W. F. AND WHIT, G. S. 1974. Biochemical genetics of hybrid sunfish: Differential survival of heterozygotes. Biochem. Genet., 11, 205-219.

WINBERG, G. G. 1956. Rate of metabolism and food requirements of fishes. Fish. Res. Bnard Can., 194, 1-253.

ZOUROS, E. 1976. Hybrid molecules and the superiority of the heterozygote. Nature, 262, 227-229.

ZOUROS, E., SINGH, S. M. AND MILES, H. E. 1980. Growth rate in oysters: an overdominant phenotype and its possible explanations. Evolution, 34, 856-867. 